\title{
A abordagem do tema educação ambiental nos trabalhos de conclusão de curso de Pedagogia da Universidade Federal de Rondônia
}

The approach to the environmental education theme in the works of completing the course of Pedagogy at the Federal University of Rondônia

El enfoque del tema de la educación ambiental en los artículos de conclusión del Curso

de Pedagogía de la Universidad Federal de Rondônia

\author{
Caroline Almeida de Andrade \\ Universidade Federal de Rondônia, Mestrado Profissional em Administração Pública \\ (PROFIAP), Porto Velho, Rondônia, Brasil \\ caroline_aandrade@hotmail.com | https://orcid.org/0000-0002-4063-3959
}

\begin{abstract}
Resumo
Neste artigo são discutidas informações sobre os trabalhos de conclusão do curso (TCC) de Pedagogia dos campi de Porto Velho e Ariquemes da Universidade Federal de Rondônia (UNIR), que abordaram o tema educação ambiental, no período de 2014 a 2018. Para a coleta dos dados foi realizada a pesquisa documental no site institucional. A abordagem no tratamento dos dados foi quantitativa, foram ilustradas as porcentagens dos trabalhos identificados com o tema educação ambiental. Constatou-se que poucos estudantes abordaram a questão do meio ambiente, não há um número significativo de trabalhos com o tema no período verificado. A abordagem do tema se deu principalmente quanto à investigação de atividades efetivas de educação ambiental realizadas no ambiente escolar. Inferiu-se que no curso de Pedagogia, a maioria dos acadêmicos ainda não demonstrou interesse na questão da preocupação ambiental para aprofundamento como trabalho de conclusão de curso. Palavras-chave: Educação Ambiental. Trabalho de Conclusão de Curso. Formação Docente.
\end{abstract}

\begin{abstract}
This article discusses information about the conclusion works of the course (TCC) of pedagogy on the campuses of Porto Velho and Ariquemes of the Federal University of Rondonia (UNIR), which addressed the theme of environmental education, from 2014 to 2018. For the collection of the data a documentary research was carried out on the institutional website. The approach in the treatment of data was quantitative, it was illustrated as percentages of the works identified with the theme of environmental education. It was found that few students addressed the issue of the environment, there is not a significant number of studies with the theme in the period verified. The theme was approached mainly regarding the investigation of effective environmental education activities carried out in schools. It was inferred that in the pedagogy course, most students still do not follow the issue of environmental concern for further study as a course conclusion.
\end{abstract}

Keywords: Environmental Education. Completion of Course Work. Teacher Training.

\section{Resumen}

En este artículo se discute información sobre los trabajos de conclusión del curso de pedagogía (TCC) de los campus de Porto Velho y Ariquemes de la Universidad Federal de Rondônia (UNIR), que abordó el tema de la educación ambiental, de 2014 a 2018. Para la colección de los datos se realizó una búsqueda documental en la web institucional. El enfoque en el tratamiento de los datos fue cuantitativo, se ilustraron los porcentajes de los trabajos identificados con el tema de educación ambiental. Se encontró que pocos estudiantes abordaron el tema del medio ambiente, no existe un número significativo de estudios con el tema en el período verificado. El tema

Artigo recebido em: 22/08/2020 | Aprovado em: 12/01/2021 | Publicado em: 01/08/2021

Como citar:

ANDRADE, Caroline Almeida de. A abordagem do tema educação ambiental nos trabalhos de conclusão de curso de Pedagogia da Universidade Federal de Rondônia. Pesquisa e Debate em Educação, Juiz de Fora: UFJF,v. 11, n. 2, p. 01-11, e31725, jul./dez. 2021. ISSN 2237-9444. DOI: https://doi.org/10.34019/2237-9444.2021.v11.31725. 
se abordó principalmente con relación a la investigación de las actividades de educación ambiental efectivas que se realizan en el ámbito escolar. Se infirió que en el curso de pedagogía, la mayoría de los estudiantes aún no han mostrado interés en el tema de la preocupación ambiental para su posterior estudio como conclusión del curso. Palabras clave: Educación ambiental. Proyecto final de curso. Educación del profesorado.

\section{Introdução}

O trabalho de conclusão de curso (TCC) é um requisito importante na graduação, obrigatório na grande maioria dos cursos. É considerado um estudo inicial de pesquisa, permite que o estudante se aprofunde em uma temática ou problema, proporcionando uma investigação em maior ou menor profundidade e com a capacidade de levantar dados de forma lógica e apresentar conclusões (OLIVEIRA, 2003).

O TCC, por muitas vezes, é o primeiro ou único contato dos alunos com a pesquisa. Nesse sentido, Corrêa, Medeiros e Sousa (2019) ressaltam que o desenvolvimento da pesquisa permite as possibilidades de formação além do ensino, pois amplia o campo de atuação dos futuros profissionais. Sendo assim, estes desenvolverão uma concepção mais crítica, além do que encerra uma formação inicial. A pesquisa como atividade científica na graduação proporciona não apenas uma análise da realidade, mas a promoção de novos conhecimentos sobre essa situação.

É clara a crescente preocupação com a questão ambiental, ao longo dos anos. Com o aumento da exploração dos recursos naturais, ocorrem em maior intensidade mudanças perceptíveis no meio ambiente. Desse modo, a educação ambiental tem a sua relevância, sobretudo no ambiente escolar em que é trabalhada de forma interdisciplinar.

O conceito de educação ambiental é definido na Lei $n^{\circ}$ 9.795/1999 sendo os processos através dos quais indivíduos e sociedade formam valores sociais, conhecimentos, habilidades, atitudes e competências direcionadas para a conservação ambiental, bem de uso comum do povo, primordial à saudável qualidade de vida e a sua sustentabilidade (BRASIL, 1999).

A educação ambiental não solucionará sozinha os profundos problemas ambientais existentes. Apesar disso, pode contribuir expressamente com a sua influência na formação do cidadão consciente dos seus direitos e deveres. Sendo ciente do problema global e agindo na sua comunidade e vice-versa, ocorrerá uma mudança no cotidiano que, se não é de resultados imediatos, visíveis, do mesmo modo não será sem efeitos concretos (REIGOTA, 2017).

Considerando que a pesquisa do TCC permite se aprofundar em determinado tema, infere-se que o tema escolhido reflete muitas vezes uma identificação do aluno com este. Nesse contexto, tratar a educação ambiental desde a formação do docente permite que este, em sua atuação em sala de aula, leve consigo e possa repassar aos seus alunos a consciência de que deve haver uma preocupação com a preservação dos recursos da natureza.

Partindo dessa elucidação, esta pesquisa levantou o seguinte problema: como é a abordagem do tema educação ambiental nos trabalhos de conclusão de curso de Pedagogia da Universidade Federal de Rondônia (UNIR)? Esta pesquisa teve 
como objetivo verificar quais trabalhos de conclusão realizados pelos acadêmicos em um período de cinco anos tiveram como temática a educação ambiental e buscou especificamente traçar o percentual dos TCC que abordam essa questão e analisar o seu desenvolvimento pelos alunos.

\section{Referencial teórico}

\subsection{Educação ambiental}

A expressão educação ambiental foi empregada mundialmente pela primeira vez em 1965, na Grã-Bretanha, durante a Conferência de Educação da Universidade de Keele. O seu maior destaque, contudo, aconteceu quando o movimento ambientalista mundial estimulou uma reação dos governos na Conferência das Nações Unidas sobre o Meio Ambiente Humano realizada em 1972, em Estocolmo, na Suécia. Em 1975 foi o Programa Internacional de Educação Ambiental (PIEA) que foi relevante instrumento para dar visibilidade aos trabalhos sobre o tema (BIASOLI, 2018).

No Brasil foi a Lei n.o 6.938 em 1981 que implementou a Política Nacional do Meio Ambiente (PNMA) e trouxe a educação ambiental como um dos seus princípios. Essa norma estabelece que o tema deve estar presente em todos os níveis de ensino. Outro avanço ocorreu na Constituição Federal em 1988, em que foi acentuada a relevância da educação ambiental, designando ao poder público a promoção desta em todos os níveis de ensino e a conscientização pública para a conservação do meio ambiente (BIASOLI, 2018).

Na comunidade internacional é unanimidade que a educação ambiental precisa estar presente em todos os espaços educacionais aos cidadãos. Portanto, pode ser exercida nas escolas, nos parques e reservas ecológicos, nas associações de bairro, nos sindicatos, nas universidades, nos meios de comunicação de massa, dentre outros. Cada um desses espaços tem as suas particularidades que contribuem para a diversidade da consciência ambiental (REIGOTA, 2017).

Os objetivos da educação ambiental são parte de um sistema total sem início ou fim. Ao obter certo conhecimento sobre o meio ambiente, as pessoas podem sensibilizar-se sobre o assunto, mudar suas atitudes e iniciar ações, assim como iniciar um ciclo, em que as habilidades obtidas levam a conhecimentos que promovam sensibilização e as conduzam à participação ou à busca de novos aprendizados em uma fase que não tem fim (BRANDALISE et al., 2015).

A conscientização ambiental é essencialmente uma questão de educação, envolve a mudança de comportamento, tanto de atividades como em aspectos da vida dos indivíduos e da sociedade no tocante ao meio ambiente. Possuir consciência ecológica é utilizar os recursos ambientais de forma sustentável, ou seja, consumir o que se pode produzir sem prejudicar o ambiente para as gerações futuras (BRANDALISE et al., 2015).

Ao longo dos anos aconteceram mudanças no pensamento quanto ao meio ambiente, o que foi ocasionado principalmente por atividades de educação ambiental, pois estas possibilitam aos educandos oportunidades para desenvolver sensibi- 
lidade aos problemas ambientais, propiciando uma reflexão e a busca de possíveis soluções para tais dificuldades. Essas atividades, provavelmente, serão um caminho para que as pessoas sejam mais conscientes da importância das suas atitudes (RODRIGUES; CARVALHO, 2016).

Nesse contexto, os cursos de formação de docente precisam preparar os acadêmicos para a educação ambiental. De acordo com as Diretrizes Curriculares Nacionais para o Curso de Graduação em Pedagogia, por meio de estudos teórico-práticos, investigação e reflexão crítica, a graduação propiciará a aplicação ao campo da educação, de contribuições, de conhecimentos ambiental-ecológico, entre outras. As diretrizes trazem também objetivos quanto ao egresso, que deverá estar apto a demonstrar consciência da diversidade, respeitando as diferenças de natureza ambiental-ecológica (BRASIL, 2006).

\subsection{Trabalho de conclusão de curso e formação docente}

O Trabalho de Conclusão de Curso faz parte do currículo em muitos cursos de graduação, sendo uma atividade relevante para o processo e aprendizagem dos alunos. Para a maioria dos alunos esse trabalho é o primeiro contato de realização de uma pesquisa. Como experiência de produção de conhecimento, favorece consideravelmente a aprendizagem, é interligado aos conteúdos do curso, às disciplinas e ao convívio com os professores (SEVERINO, 2017).

O TCC pode ser teórico, documental ou pesquisa de campo. Sejam quais forem as formas de abordagem, a atividade destina-se a organizar e consolidar o processo de formação do aluno, idealizando o conhecimento científico em sua área. Sendo assim, é uma oportunidade para o estudante aprofundar-se em um tema de grande relevância dentre seus estudos de graduação (SANTOS; CANDELORO, 2006; SEVERINO, 2017).

O caminho mais adequado aos alunos, inclusive para que consigam alcançar os objetivos da própria aprendizagem, é o envolvimento destes ainda na fase de graduação em ações sistemáticas de produção do conhecimento científico, e que assim possam se familiarizar com as práticas teóricas e empíricas da pesquisa. Desse modo, é possível inferir que a iniciação à prática científica na universidade precisa de mediações curriculares que desenvolvam, simultânea e equilibradamente, uma legitimação político-educacional do conhecimento, sua fundamentação epistemológica, uma estratégia didático-metodológica e uma metodologia técnica aplicada (SEVERINO, 2008).

As recentes demandas exigidas na formação docente trazem como consequência a necessidade de se praticar a renovação no âmbito da sala de aula e nas metodologias de ensino universitário, o que traz implicações novas para os docentes em seu trabalho formativo. Nessa nova perspectiva, as concepções didáticas clássicas, que estão centradas na aula e na atuação do professor, têm que ceder espaço a métodos de ensino concentrados na autonomia dos alunos no exercício das atividades, implantar novas maneiras de planejar e executar o processo de ensino-aprendizagem. Portanto, demanda novas habilidades dos docentes, que possam favorecer o desenvolvimento de outras dimensões na formação dos alunos, existe a necessidade de constituição de um novo paradigma de docência universitária (ALMEIDA; PIMENTA, 2020). 
De acordo com o Projeto Político Pedagógico do Curso (PPP) de Pedagogia da UNIR, a formação do pedagogo caracterizará a pesquisa como princípio epistemológico e formativo, fazendo o profissional nele envolvido um sujeito pesquisador de suas práticas educativas e das relações que estas estabelecem com contextos e sujeitos de interação. A prática do pedagogo é, então, uma prática da pesquisa, mas primeiro, é uma ação para o exercício pleno da cidadania (UNIVERSIDADE FEDERAL DE RONDÔNIA, 2013).

O PPP traz ainda que a interdisciplinaridade como diretriz teórico-metodológica se dá na perspectiva de alcançar a síntese dos conhecimentos, não apenas pela integração dos saberes produzidos nas diversas éreas do estudo, mas pela associação dialética entre teoria e prática, ação e reflexão, ensino, avaliação e aprendizagem, conteúdo e processo (UNIVERSIDADE FEDERAL DE RONDÔNIA, 2013).

Nesse sentido, a formação de professores, a iniciação científica, assim como o TCC se mostram como relevantes atividades de pesquisa, porém, poucos alunos têm a oportunidade de participar de programas de iniciação científica, assim o TCC se torna a principal atividade na formação inicial. A pesquisa como princípio educativo rompe com o modelo que pretende só ensinar (MOURA, 2017).

Destaca-se, portanto, que no processo de elaboração do TCC são notáveis as possibilidades e materialidades da formação política do pedagogo. É um trabalho formativo que vai além das discussões disciplinares e se expande em todo contexto da universidade e suas oportunidades efetivas de debate, saberes e execução política. Os reflexos da formação explicitam-se nas temáticas de pesquisa, que em muitas vezes carregam em sua essência preocupações políticas e preconizam trabalhos que, na própria revisão de literatura, possibilitam discussões que denotam preocupações com a sociedade (OLIVEIRA, 2012).

\section{Metodologia}

Quanto à abordagem do problema, esta pesquisa é de cunho quantitativo. A pesquisa captou informações sobre os trabalhos de conclusão do curso de Pedagogia da Universidade Federal de Rondônia, que abordaram o tema educação ambiental. 0 estudo abrangeu os campi localizados nos municípios de Porto Velho e Ariquemes e foi referente ao período de 2014 a 2018. Foram ilustradas as porcentagens dos trabaIhos identificados com o tema. O levantamento das informações buscou descrever os trabalhos pesquisados, utilizando instrumento padrão de coleta de dados, que conduzem a resultados de natureza quantitativa, conforme afirma Gil (2002).

Por ter como objetivo a descrição das características de determinado fenômeno, esta pesquisa será descritiva, pois será efetuado levantamento, registro, análise e correlação das temáticas abordadas nos TCC, correlacionando aos fatos sem manipulá-los. Acrescenta-se que na pesquisa descritiva procura-se descobrir, com a precisão possível, a frequência com que um fenômeno ocorre e conexão com os outros, sua natureza e características (CERVO; BERVIAN, 1996).

Para coleta dos dados foi realizada pesquisa documental. A etapa de pesquisa documental foi realizada em materiais que ainda não tiveram nenhum tratamento analítico, sendo, portanto, ainda matéria-prima a partir da qual o pesquisador desenvolve sua investigação e análise, como asseveram Cervo e Bervian (1996) e Severino (2017). 
A pesquisa documental foi realizada nos sites oficiais da instituição, especificamente a página do Departamento Acadêmico de Educação e o repositório institucional da UNIR. Procurou-se primeiramente no título dos trabalhos por palavras que remetessem ao tema: meio ambiente, educação ambiental ou sustentabilidade. Posteriormente foram analisados os resumos, palavras-chave e objetivos do trabalho. Para completação de dados foram consultados o projeto pedagógico do curso e grade curricular.

\section{Resultados e discussões}

Foram identificados um total de cento e cinquenta e três (153) trabalhos de conclusão de curso dos alunos e, conforme Tabela 1, foi possível verificar que no período apenas seis (6) TCCs abordaram a educação ambiental. Nos anos de 2014 e 2017 não houve pesquisas na temática, sendo o ano de 2015 o que teve mais apresentações acerca da questão meio ambiente. A análise quantitativa demonstrou que cerca de $5 \%$ dos trabalhos trataram do tema.

Tabela 1: Quantidade de TCCs com o tema educação ambiental

\begin{tabular}{ccc}
\hline Ano & Total de produções & $\begin{array}{c}\text { Trabalhos com o tema } \\
\text { educação ambiental }\end{array}$ \\
\hline 2014 & 17 & 0 \\
\hline 2015 & 50 & 3 \\
\hline 2016 & 37 & 1 \\
\hline 2017 & 20 & 0 \\
\hline 2018 & 29 & 2 \\
\hline Total & 153 & 6 \\
\hline
\end{tabular}

Fonte: Elaborado pela autora com base nos dados coletados na pesquisa.

Não foi possível identificar explicitamente o termo educação ambiental em todos os trabalhos, porém, como um destes continha a expressão sustentabilidade, evidentemente pôde ser identificado que tratava da questão do meio ambiente. Um ponto a ser destacado é que em dois dos trabalhos a pesquisa foi em escolas rurais, espaço no qual os alunos normalmente estão mais conectados com o meio ambiente.

Outro ponto a ser destacado é que todos os trabalhos tiveram como método a pesquisa de campo. Essa metodologia permite aos pesquisadores se aprofundarem na vivência da unidade pesquisada, neste caso, as escolas em que coletaram os dados. Possibilita, portanto, melhor percepção dos maiores desafios e viabilidades na abordagem do meio ambiente em sala de aula. Provavelmente esses egressos levarão para a sua realidade em sua conduta profissional as experiências que adquiriram no processo de elaboração do TCC. Os trabalhos que trataram do tema educação ambiental estão especificados no Quadro 1. 
Quadro 1: Relação dos TCCs com o Tema Educação Ambiental

\begin{tabular}{|l|l|l|}
\hline Ano & \multicolumn{1}{|c|}{ Título } & \multicolumn{1}{|c|}{ Palavras-chave } \\
\hline 2015 & $\begin{array}{l}\text { Educação Ambiental um Estudo a } \\
\text { partir da Representação Social }\end{array}$ & $\begin{array}{l}\text { Alunos; Educação Ambiental; Representa- } \\
\text { ção Social }\end{array}$ \\
\hline 2015 & $\begin{array}{l}\text { Pedagogia da Alternância Forma- } \\
\text { ção e Sustentabilidade no Campo }\end{array}$ & $\begin{array}{l}\text { Educação; Escolas; Famílias Agrícolas em } \\
\text { Rondônia; Pedagogia da Alternância; Fa- } \\
\text { mília; Sustentabilidade no Campo }\end{array}$ \\
\hline 2016 & $\begin{array}{l}\text { Educação Formal e Sustentabili- } \\
\text { dade Ambiental: estudo de caso } \\
\text { quemes/Ro em escola pública de Ari- }\end{array}$ & $\begin{array}{l}\text { Sustentabilidade Ambiental; Educação } \\
\text { Ambiental; Educação Formal }\end{array}$ \\
\hline $\begin{array}{l}\text { Educação Ambiental: Parque Bo- } \\
\text { tânico e Banco de Sementes como } \\
\text { Ferramenta para Escolas Públicas } \\
\text { no Município de Ariquemes-RO }\end{array}$ & $\begin{array}{l}\text { Banco de Sementes; Educação Ambiental; } \\
\text { Parque Botânico }\end{array}$ \\
\hline 2018 & $\begin{array}{l}\text { Educação Ambiental: análise de } \\
\text { ensino nos anos iniciais do ensino } \\
\text { fundamental em Ariquemes - Ro }\end{array}$ & $\begin{array}{l}\text { Educação; Educação ambiental; Temas } \\
\text { transversais }\end{array}$ \\
\hline $\begin{array}{l}\text { A Educação Ambiental na Escola } \\
\text { Ribeirinha: análises etnográficas } \\
\text { na escola municipal Dra. Ana Ade- } \\
\text { laide }\end{array}$ & $\begin{array}{l}\text { Educação; Escola Ambiental; Escola Ribei- } \\
\text { rinha }\end{array}$ \\
\hline
\end{tabular}

Fonte: Elaborado pela autora com base nos dados coletados na pesquisa.

O ano de 2015 teve três trabalhos com a temática. Um dos trabalhos trouxe expressamente no título o termo educação ambiental, o estudo teve como objetivo analisar na perspectiva da representação social a percepção que os alunos de uma turma do 50 ano do ensino fundamental têm a respeito da educação ambiental e identificar e caracterizar as percepções a partir dessa realidade. A referida pesquisa buscou conhecer qual a contribuição das compreensões ambientais de alunos do ensino fundamental para a consciência ambiental sob o olhar das representações sociais.

Em outro trabalho no ano de 2015, apesar de o título não apresentar expressamente o termo educação ambiental, foi possível verificar que a monografia explorou o tema ao tratar de questões relacionadas à sustentabilidade e a escola. 0 estudo teve como objetivo investigar os principais desafios da pedagogia da alternância para assegurar a formação e a sustentabilidade do campo, especificamente no ensino do jovem do campo e auxílio da pedagogia da alternância em prol dessa sustentabilidade.

O terceiro trabalho no ano de 2015 também foi mais voltado para a perspectiva da sustentabilidade na escola, focou mais em ações práticas da instituição pesquisada, do que na abordagem da educação ambiental na sala de aula. Este trabalho teve como objetivo entender como a escola está desenvolvendo ações de cunho ambiental e buscou identificar as necessidades e a importância de se trabalhar e desenvolver atividades voltadas para sustentabilidade no âmbito da escola. 
No ano de 2016 a pesquisa identificada teve como objeto principal as ações de educação ambiental realizadas em duas escolas de nível fundamental, desenvolvidas pelo Parque Botânico localizado no Município de Ariquemes em Rondônia. 0 objetivo foi identificar aspectos referentes a esse parque e seu banco de sementes e como se desenvolveram as ações nas escolas.

No ano de 2018 foram localizados dois trabalhos sobre educação ambiental, um destes teve como objetivo apresentar uma atualização da condição das escolas ribeirinhas em relação ao tratamento das questões básicas no sentido ambiental. 0 trabalho buscou investigar as ações práticas que estavam sendo propostas à turma estudada em uma relação direta com a proposta presente na legislação educacional da educação ambiental e em outros tratados nacionais e internacionais.

No outro trabalho no ano de 2018 a abordagem foi quanto à forma como a temática foi trabalhada nos anos iniciais do ensino fundamental nas escolas públicas no município de Ariquemes. A pesquisa buscou responder como as instituições de ensino público abordaram o tema educação ambiental em sua prática pedagógica e como os professores transmitiram esse conceito para o aluno, de acordo com as políticas educacionais do governo federal brasileiro.

Alguns fatores podem contribuir na escolha do tema do TCC pelo aluno, como a matriz curricular, afinidade com professores da disciplina, facilidade com o assunto, interesse pessoal, dentre outros. Na matriz curricular do curso de Porto Velho foi possível localizar uma disciplina com foco na questão do meio ambiente: Fundamentos e Prática do Ensino de Ciências e Educação Ambiental, com carga horária de 80 horas.

No campus de Ariquemes é ofertada a disciplina Educação do Campo e Desenvolvimento Sustentável, com carga horária de 80 horas, e a disciplina Fundamentos e Prática do Ensino de Ciência, com carga horária de 80 horas, que também possui em sua ementa aspectos referentes à educação ambiental.

O Projeto Político Pedagógico do Curso (PPP) de Pedagogia da UNIR, campus Porto Velho, trouxe princípios quanto à formação do pedagogo envolvendo aspectos ambientais. No direcionamento do currículo, o curso está constituído por um conjunto de conhecimentos que qualifica o graduando para, entre outros aspectos, compreender o ser humano, a sociedade e a natureza, e ainda realizar pesquisas sobre processos de aprendizagem em diferentes contextos socioambientais (UNIVERSIDADE FEDERAL DE RONDÔNIA, 2013).

No projeto pedagógico do curso de Pedagogia, licenciatura, campus de Ariquemes, também foi possível identificar alguns aspectos de ênfase na questão ambiental. O curso tem como um de seus objetivos acentuar o conhecimento científico da região amazônica, nas dimensões econômico-social, ambiental e cultural. E ainda traz que o curso deve buscar uma formação para a sustentabilidade, com o pensamento de um desenvolvimento, em que a eficiência econômica e tecnológica considere essenciais a equidade social e a sustentabilidade ambiental. (UNIVERSIDADE FEDERAL DE RONDÔNIA, 2016). 


\section{Considerações finais}

Em relação aos objetivos propostos para esta pesquisa, foi possível identificar quantos trabalhos de conclusão realizados pelos acadêmicos tiveram como tema a educação ambiental e como foi trabalhado. Especificamente foi traçado o percentual dos TCC que abordaram o tema ambiental e analisado o desenvolvimento da temática pelos alunos.

A partir da análise desses dados obtidos, quanto ao problema levantado, foi possível verificar que não há um número significativo de pesquisas com o tema educação ambiental nos trabalhos de conclusão de curso no período verificado, sendo um baixo percentual, considerando o total identificado. A abordagem do tema se deu principalmente quanto à investigação de como a educação ambiental é trabalhada na sala de aula em escolas.

Como conclusão geral, pode-se inferir que embora cada vez mais a preocupação com o problema ambiental venha se expandindo, nota-se que na graduação de pedagogia da UNIR a maioria dos alunos ainda não demonstrou interesse pela questão do meio ambiente para aprofundamento como pesquisa de TCC.

Portanto, ressalta-se aqui a importância de se dar mais destaque e incentivo aos alunos da graduação para atividades de educação ambiental, visto que geralmente o aluno, ao escolher a área em que desenvolverá seu tema de trabalho, opta por aquela com a qual tem maior afinidade ou em que tem mais conhecimento. No curso de Pedagogia nos campi pesquisados, em relação à oferta de disciplinas com foco especificamente na dimensão ambiental, identificou-se no campus de Porto Velho apenas uma disciplina, e no campus de Ariquemes, duas disciplinas. É relevante nesse sentido que se possa desenvolver a temática na perspectiva transversal nas diversas disciplinas da grade curricular, no decorrer da formação. Ao se dar maior relevância ao tema, são maiores as possibilidades de interesse dos alunos de graduação, futuros professores, que levarão consigo essa consciência e repassarão aos seus alunos em sala de aula na escola.

\section{Referências}

ALMEIDA, Maria Isabel de; PIMENTA, Selma Garrido. Pedagogia universitária: valorizando o ensino e à docência na universidade. In: BARREIRO, Iraíde Marques de Freitas; BARBOSA, Raquel Lazzari Leite (Orgs). Formação de educadores: inovação e tradição: preservar e criar na formação docente. São Paulo: Unesp Digital, 2020.

BIASOLI, Semíramis. Fundamentos de educação ambiental para sustentabilidade. São Paulo: Senac, 2018.

BRANDALISE, L. T.; BERTOLINI, G, R, F.; HOSS, O.; ROJO, C. A. Educação e gestão ambiental: sustentabilidade em ambientes competitivos. Paraná: DRHS, 2015.

BRASIL. Lei no 9.795 de 27 de abril de 1999. Dispõe sobre a educação ambiental e institui a Política Nacional de Educação Ambiental e dá outras providências. Disponível em: http://www.planalto.gov.br/ccivil 03/leis/19795.htm. Acesso em: 28 jan. 2020. 
BRASIL. Ministério da Educação. Conselho Nacional de Educação. Resolução CNE/CP № 1, de 15 de maio de 2006. Institui Diretrizes Curriculares Nacionais para o Curso de Graduação em Pedagogia, licenciatura. Diário Oficial da União, seção 1, Brasília, DF, p. 1, 16 maio 2006.

CERVO, Amado Luiz; BERVIAN, Pedro Alcino. Metodologia científica. 4 ed. São Paulo: MAKRON Books, 1996.

CORRÊA, Ana Jéssica; MEDEIROS, Danyella Martins; SOUSA, Fernando Santos. A pesquisa como elemento estruturante da formação de professores e sua ação no ensino superior. In: DANTAS, Otília Maria Alves da Nóbrega Alberto (Org.). Profissão docente: formação, saberes e práticas. Jundiaí: Editorial, 2019.

GIL, Antônio Carlos. Como elaborar projetos de pesquisa. 4. ed. São Paulo: Atlas, 2002. MOURA, Josiel da Rosa. Contribuições do TCC para a formação de professores pedagogos: um estudo, de caso em uma instituição de ensino superior. 2017. Dissertação (Mestrado em Educação) - Pontifícia Universidade Católica do Rio Grande do Sul, Porto Alegre, 2017.

OLIVEIRA, Glória Aparecida Pereira de. A concepção de egressos de um curso de pedagogia acerca da contribuição do trabalho de conclusão de curso. 2003. Dissertação (Mestrado em Educação) - Universidade Estadual de Campinas, Campinas, 2003.

OLIVEIRA, Renata Greco de. Formação do pedagogo na universidade: o espaço do político no trabalho de conclusão de curso. 2012. Dissertação (Mestrado em Educação) - Universidade Federal do Rio Grande do Sul, Porto Alegre, 2012.

REIGOTA, Marcos. O que é educação ambiental. São Paulo: Brasiliense, 2017.

RODRIGUES, Maria Helena Quaiati; CARVALHO, Milena Rodrigues. Práticas de educação ambiental: metodologia de projetos. Curitiba: Appris, 2016.

SANTOS, Vanice dos; CANDELORO, Rosana J. Trabalhos acadêmicos: uma orientação para pesquisa e normas técnicas. Porto Alegre: AGE, 2006.

SEVERINO, Antonio Joaquim. Ensino e pesquisa na docência universitária: caminhos para a integração. São Paulo: USP, 2008. E-book. Disponível em: http://www.prpg.usp. br/attachments/article/640/Caderno 3 PAE.pdf. Acesso em: 29 jul. 2020.

SEVERINO, Antônio Joaquim. Metodologia do Científico. São Paulo: Cortez, 2017.

UNIVERSIDADE FEDERAL DE RONDÔNIA. Projeto pedagógico: curso de licenciatura em pedagogia. Ariquemes, 2016. Disponível em: http://www.deced.arq. unir.br/uploads/07010701/arquivos/Projeto Pedag gico do Curso de Pedagogia 2016 663083059.pdf. Acesso em: 18 ago. 2020.

UNIVERSIDADE FEDERAL DE RONDÔNIA. Projeto político-pedagógico: curso de graduação em pedagogia, licenciatura. Porto Velho, 2012. Disponível em: http://www. ded.unir.br/uploads/04155632/arquivos/PROJETO POLITICO PEDAGOGICO DO CURSO DE PEDAGOGIA 416552329.pdf. Acesso em: 17 ago. 2020. 
Preprint, originalidade e ineditismo

O artigo é original, inédito e não foi depositado como preprint.

Consentimento de uso de imagem

Não se aplica.

Aprovação de Comitê de Ética em Pesquisa

Não se aplica.

Conflito de interesse

Não há conflitos de interesse.

Conjunto de dados de pesquisa

Não há dados disponibilizados.

Licença de uso

Os autores cedem à Revista Pesquisa e Debate em Educação os direitos exclusivos de primeira publicação, com o trabalho simultaneamente licenciado sob a Licença Creative Commons Attribution (CC BY) 4.0 International. Esta licença permite que terceiros remixem, adaptem e criem a partir do trabalho publicado, atribuindo o devido crédito de autoria e publicação inicial neste periódico. Os autores têm autorização para assumir contratos adicionais separadamente, para distribuição não exclusiva da versão do trabalho publicada neste periódico (ex.: publicar em repositório institucional, em site pessoal, publicar uma tradução, ou como capítulo de livro), com reconhecimento de autoria e publicação inicial neste periódico.

Publisher

Universidade Federal de Juiz de Fora (UFJF), Faculdade de Educação (FACED), Centro de Políticas Públicas e Avaliação da Educação (CAEd), Programa de Pós-Graduação Profissional em Gestão e Avaliação da Educação Pública (PPGP). Publicação no Portal de Periódicos da UFJF. As ideias expressadas neste artigo são de responsabilidade de seus autores, não representando, necessariamente, a opinião dos editores ou da universidade.

\section{Editores}

Frederico Braida; Liamara Scortegagna; Wagner Silveira Rezende.

Sobre a autora

Caroline Almeida de Andrade

Graduada em Ciências Biológicas, Universidade Federal de Rondônia(UNIR).

Graduada em Administração, Universidade Federal de Rondônia(UNIR). Especialista em Metodologia do Ensino Superior, Faculdade Católica de Rondônia (FCR). Especialista em Gestão Pública, Centro Universitário Claretiano de Batatais(CEUCLAR). Mestra em Administração Pública, Universidade Federal de Rondônia(UNIR) . Técnica em Assuntos Educacionais na Universidade Federal de Rondônia(UNIR). Currículo Lattes: http://lattes.cnpq.br/6614485444384111 